\title{
GAMBARAN HASIL CT SCAN KEPALA PADA PENDERITA DENGAN KLINIS STROKE NON-HEMORAGIK DI BAGIAN RADIOLOGI FK. UNSRAT / SMF RADIOLOGI BLU RSUP PROF. DR. R. D KANDOU MANADO PERIODE JANUARI 2011- DESEMBER 2011
}

\author{
${ }^{1}$ Mohammad Arswendo Tjikoe \\ ${ }^{2}$ Elvie Loho \\ ${ }^{2}$ Ramli H. Ali \\ ${ }^{1}$ Kandidat Skripsi Fakultas Kedokteran Universitas Sam Ratulangi Manado \\ ${ }^{2}$ Bagian Radiologi Fakultas Kedokteran Universitas Sam Ratulangi Manado \\ Email: edhograph@yahoo.com
}

\begin{abstract}
Stroke is the most common of neurologic manifestations and easily recognizable from the other neurologic diseases due to the early onset of sudden in a short time. Stroke as clinical diagnosis was divided to hemorrhagic stroke and ischemic stroke. In hemorrhagic stroke there is a rupture in blood vessel so the blood flow became abnormal and bleeds into surrounding brain and damage it. In ischemic stroke the blood flow heading to the brain is interrupted due to atherosclerosis process. The purpose of this study is to know about description of head CT scan in patient with clinical diagnonis of stroke non hemorrhagic in Department/SMF Radiology Faculty Of Medicine UNSRAT BLU RSUP Prof. Dr. R. D. Kandou Manado period on $1^{\text {st }}$ January 2011 - 31 ${ }^{\text {st }}$ December 2011. Methods: The study design was a retrospective descriptive study. The data are from request form sheet and radiographic response in the Department of Radiology and processed in descriptive. Results: Base on 163 data of stroke patients obtained, 74 patients diagnosed with infarction stroke (45,4\%). Male had more (59,5\%) than female (40,5\%). For age group, 60-79 is the largest with 33 patients $(44,6 \%)$. Area with most lesion was in parietal dextra lobe with 8 cases (10,8\%). Most cases was happened in August with 10 cases $(13,5 \%)$. Conclusion: Patients with radiology diagnosis infarction stroke, the most common infarction location is in parietal dextra area.
\end{abstract}

Keywords: CT Scan, Infarction Stroke, Parietal Dextra.

\begin{abstract}
Abstrak: Stroke merupakan salah satu manifestasi neurologik yang umum, dan mudah dikenal dari penyakit-penyakit neurologik lain karena mula timbulnya mendadak dalam waktu yang singkat. Stroke sebagai diagnosis klinis terbagi menjadi stroke hemoragik (pendarahan) dan stroke non-hemoragik (iskemik). Pada stroke hemoragik pembuluh darah pecah sehingga aliran darah menjadi tidak normal dan darah yang keluar merembes masuk ke dalam suatu daerah di otak dan merusaknya. Sedangkan pada stroke non-hemoragik aliran darah ke otak terhenti karena aterosklerosis atau bekuan darah yang telah menyumbat suatu pembuluh darah, melalui proses aterosklerosis. Tujuan penelitian ini adalah untuk mengetahui gambaran hasil CT scan kepala pada penderita dengan klinis stroke non-hemoragik di Bagian Radiologi FK. Unsrat / SMF Radiologi BLU RSUP Prof. dr. R. D Kandou Manado periode Januari 2011- Desember 2011. Metode: Penelitian ini merupakan penelitian deskriptif retrospektif dengan memanfaatkan data sekunder berupa lembaran permintaan \& jawaban CT scan kepala yang terdapat di bagian Radiologi BLU RSUP Prof. Dr. R. D. Kandou Manado periode 1 Januari 2011 - 31 Desember 2011. Hasil penelitian: Berdasarkan 163 data pasien yang didapatkan, 74 pasien didiagnosis dengan stroke infark (45,4\%). Laki-laki lebih banyak (59,5\%) dari perempuan (40,5\%). Kelompok umur 60-79 merupakan kelompok umur terbanyak yaitu 33 pasien (44,6\%). Daerah lesi terbanyak adalah pada daerah parietalis dextra dengan 8 kasus (10,8\%). Kasus terbanyak terjadi pada bulan agustus dengan 10 kasus (13,5\%). Simpulan: Pada pasien dengan diagnosis radiologi stroke infark, lokasi infark yang paling banyak muncul adalah terdapat pada daerah parietal dextra.
\end{abstract}

Kata kunci: CT Scan, Stroke Infark, Parietal Dextra. 
Stroke merupakan salah satu manifestasi neurologik yang umum, dan mudah dikenal dari penyakit-penyakit neurologik lain karena mula timbulnya mendadak dalam waktu yang singkat. ${ }^{1}$ Insiden stroke meningkat sejalan dengan usia dan lebih sering terjadi pada pria dibandingkan wanita. Faktor-faktor resiko yang signifikan untuk stroke adalah hipertensi, hiperkolesterolemia, diabetes melitus, merokok, komsumsi minuman keras, dan penggunaan kontrasepsi oral. $^{2}$

Sekitar 50\% CVA (Cerebrovascular Accident/Stroke) terjadi pada mereka yang berusia 70 tahun. Namun, perbandingan kejadian stroke pada individu yang lebih muda dan mereka yang berusia 65 tahun adalah 3:10 atau sekitar 28\% stroke juga terjadi pada individu yang lebih muda. ${ }^{3}$

Stroke sering melumpuhkan dari pada mematikan. Kira-kira 30\% penderita stroke yang bertahan hidup tidak bisa pulih sepenuhnya dan sekitar 20\% membutuhkan bantuan untuk keperluan hidup sehari-hari. Penyakit cerebrovascular adalah penyebab pertama kecacatan jangka panjang serius di Amerika Serikat (American Heart Association, 2004) dan merupakan urutan kedua di seluruh dunia, pada individu yang berusia lebih dari 60 tahun (WHO,2003). ${ }^{4}$

Data Riskesdas (Riset kesehatan dasar) tahun 2007 menunjukkan bahwa stroke merupakan penyebab kematian nomor satu di Indonesia dengan prevalensi 8,3 per 1000 penduduk dan menjadi penyebab kematian utama di rumah sakit, yakni sebesar 15,4\%. Penelitian yang dilakukan di 33 provinsi diperoleh Sulawesi Utara menempati urutan ke-4 dalam jumlah penderita stroke, yakni 8,5\% penduduk terdiagnosis. ${ }^{5}$ Mengingat tingginya angka kejadian stroke tersebut maka diperlukan diagnosis stroke seawal mungkin untuk menentukan terapi yang sesuai, sehingga diharapkan dapat menurunkan angka kematian yang disebabkan stroke. Stroke sebagai diagnosis klinis terbagi menjadi stroke hemoragik (pendarahan) dan stroke non-hemoragik (iskemik). ${ }^{6,7}$
Oleh karena itu, untuk membedakan antara stroke hemoragik dan non-hemoragik saat ini telah rutin dilakukan pemeriksaan CT scan sebagai gold standard. Pada pemeriksaan CT scan akan didapatkan gambaran abnormal yang berbeda antara stroke hemoragik dan non-hemoragik. Lesi berupa perdarahan akan didapatkan pada stroke hemoragik sedangkan lesi iskemik atau infark otak akan didapatkan pada stroke non-hemoragik. ${ }^{7,8}$

Berdasarkan uraian diatas, maka penulis berkeinginan untuk melakukan penelitian mengenai gambaran hasil CT scan pada pasien dengan klinis stroke nonhemoragik di bagian Radiologi FK Unsrat / SMF Radiologi BLU RSUP Prof. Dr. R. D. Kandou Manado.

\section{METODOLOGI PENELITIAN}

Penelitian ini merupakan penelitian deskriptif retrospektif dengan memanfaatkan data sekunder berupa lembaran permintaan \& jawaban CT scan kepala yang terdapat di bagian Radiologi BLU RSUP Prof. Dr. R. D. Kandou Manado periode 1 Januari 2011 - 31 Desember 2011. Populasi penelitian yaitu semua lembaran permintaan \& jawaban CT scan kepala, sedangkan sampel yang penelitian yaitu semua lembaran permintaan \& jawaban CT scan kepala penderita dengan dugaan klinis stroke non hemoragik.

Alat dan bahan yang digunakan untuk penelitian ini yaitu buku teks, E-book, jurnal, alat tulis menulis serta lembaran permintaan dan jawaban CT scan kepala penderita dengan klinis stroke nonhemoragik di bagian Radiologi BLU RSUP Prof. DR. R. D. Kandou Manado periode 1 Januari 2011 - 31 Desember 2011.

Variabel penelitian yang diteliti yaitu:

1. Lembaran permintaan \& jawaban CT Scan

2. Umur

3. Jenis kelamin

4. Kasus per bulan

5. Gambaran hasil CT scan kepala 
Tjikoe, Loho, Ali; Gambaran Hasil CT-Scan Kepala pada Penderita...

Cara kerja pada penelitian ini yaitu Data dikumpulkan secara retrospektif dari lembaran permintaan CT scan kepala penderita dengan dugaan klinis stroke non hemoragik di bagian Radiologi BLU RSUP Prof. Dr. R. D. Kandou Manado, dalam kurun waktu 1 tahun.Data yang terkumpul kemudian diolah dan disajikan dalam bentuk grafik dan table (dalam presentasi).

\section{HASIL PENELITIAN}

Berdasarkan data yang diambil dari Bagian Radiologi FK. Unsrat/SMF Radiologi BLU RSUP. Prof. Dr. R.D Kandou Manado periode Januari 2011 Desember 2011, didapatkan penderita dengan dugaan klinis Stroke Non Hemoragik sebanyak 163 kasus.

Berdasarkan data yang diambil dari Bagian Radiologi FK. Unsrat/SMF Radiologi BLU RSUP. Prof. Dr. R.D Kandou Manado periode Januari 2011 Desember 2011, didapatkan penderita dengan dugaan klinis Stroke Non Hemoragik sebanyak 163 kasus.

Tabel 4.1 : Distribusi penderita Stroke menurut Diagnosis Radiologi

\begin{tabular}{ccc}
\hline Diagnosis Radiologi & Jumlah Penderita & Presentase (\%) \\
\hline Stroke Infark & 74 & 45,4 \\
Bukan Stroke Infark & 89 & 54,6 \\
\hline Total & $\mathbf{1 6 3}$ & $\mathbf{1 0 0}$ \\
\hline
\end{tabular}

Dari tabel 4.1 didapatkan data sebanyak 74 orang $(45,4 \%)$ yang melakukan pemeriksaan CT Scan di Bagian Radiologi FK. Unsrat / SMF Radiologi BLU RSUP. Prof. Dr. R.D Kandou Manado periode Januari 2011 - Desember 2011 di diagnosis dengan Stroke Infark, sedangkan yang bukan Stroke Infark sebanyak 89 orang (54,6\%).
Tabel 4.2 : Distribusi penderita Stroke Infark berdasarkan jenis kelamin

\begin{tabular}{ccc}
\hline Jenis Kelamin & Jumlah Penderita & Presentase (\%) \\
\hline Laki-laki & 44 & 59,5 \\
Perempuan & 30 & 40,5 \\
\hline Total & & $\mathbf{1 0 0}$ \\
\hline
\end{tabular}

Berdasarkan keterangan dari tabel 4.2 jumlah penderita Stroke Infark yang berjenis kelamin laki-laki adalah sebanyak 44 orang (59,5\%) sedangkan jumlah penderita yang berjenis kelamin perempuan adalah sebanyak 30 orang $(40,5 \%)$.

Tabel 4.3 : Distribusi penderita Stroke Infark berdasarkan umur

\begin{tabular}{ccc}
\hline Umur (tahun) & Jumlah Penderita & Presentase (\%) \\
\hline $20-30$ & 5 & 6,8 \\
$40-59$ & 29 & 39,2 \\
$60-79$ & 33 & 44,6 \\
$>80$ & 7 & 9,4 \\
\hline Total & $\mathbf{7 4}$ & $\mathbf{1 0 0}$ \\
\hline
\end{tabular}

Berdasarkan data dari tabel 4.3, kelompok umur 60-79 tahun memiliki penderita Stroke Infark terbanyak dari seluruh kelompok dengan jumlah penderita sebanyak 33 orang (44,6\%), sedangkan kelompok umur 20-30 tahun yang tersedikit dengan jumlah penderita 5 orang $(6,8 \%)$. 
Tabel 4.4 : Distribusi Stroke Infark berdasarkan kasus per bulan

\begin{tabular}{|c|c|c|}
\hline Bulan & Jumlah & Presentase(\%) \\
\hline Januari & 7 & 9,5 \\
\hline Februari & 6 & 8,1 \\
\hline Maret & 1 & 1,3 \\
\hline April & 9 & 12,2 \\
\hline Mei & 9 & 12,2 \\
\hline Juni & 4 & 5,4 \\
\hline Juli & 2 & 2,7 \\
\hline Agustus & 10 & 13,5 \\
\hline September & 8 & 10,8 \\
\hline Oktober & 6 & 8,1 \\
\hline November & 4 & 5,4 \\
\hline Desember & 8 & 10,8 \\
\hline Total & 74 & 100 \\
\hline
\end{tabular}

Berdasarkan data yang diperoleh dari tabel 4.4 dapat dilihat bahwa kasus terbanyak terjadi pada bulan Agustus yaitu 10 kasus (13,5\%), dan kasus tersedikit yaitu pada bulan Maret dengan 1 kasus (1,3\%).

\section{BAHASAN}

Dari hasil penelitian yang dilakukan secara deskriptif retrospektif yaitu dengan mengambil data yang terdapat dibagian Radiologi FK. Unsrat / SMF Radiologi BLU RSUP. Prof. Dr. R.D Kandou Manado periode Januari 2011 - Desember 2011, pada tabel 4.1 didapatkan data sebanyak 74 pasien $(45,4 \%)$ dengan diagnosis radiologi Stroke Infark, sedangkan sebanyak 89 pasien $(54,6 \%)$ bukan stroke infark. Hasil yang kurang lebih sama dengan penelitian yang dilakukan oleh Krisnarta (2010) yang mendapatkan data sebanyak $41,3 \%$ pasien iskemik, dan 58,7\% bukan stroke iskemik. ${ }^{9}$

Pada tabel 4.2, hasil penelitian mendapatkan data bahwa pasien laki-laki lebih banyak yang menderita Stroke Non
Hemoragik yaitu sebanyak 44 orang (59,5\%) dibandingkan perempuan dengan 30 orang (40,5\%). Hal serupa juga terdapat pada penelitian yang dilakukan oleh Airboix, dkk. (2010) yang mendapatkan data perbandingan laki-laki dan perempuan yang menderita stroke iskemik sebesar 57,7\% berbanding 42,3\%. ${ }^{10}$ Pada penelitian yang dilakukan oleh Feigin, dkk. (1998) juga dijumpai jumlah pasien laki-laki lebih banyak daripada pasien wanita dengan perbandingan $60 \%$ berbanding $40 \%{ }^{11}$ Hal ini juga sesuai dengan penelitian oleh Pendlebury S, dkk. (2009) yang mengatakan insidensi pada laki-laki cenderung lebih tinggi daripada pada perempuan. ${ }^{12}$

Pada tabel 4.3 kelompok umur dibagi menjadi 4, dimana kelompok umur 60-79 tahun memiliki jumlah pasien terbanyak yaitu sebanyak 33 pasien (44,6\%), selanjutnya pada kelompok umur 40-59 tahun terdapat 29 pasien $(39,2 \%)$, diikuti kelompok umur $>80$ tahun sebanyak 7 pasien $(9,4 \%)$, dan yang terakhir pada kelompok umur 20-39 tahun dengan 5 pasien (6,8\%). Hal ini sesuai dengan data dari penelitian yang dilakukan oleh oleh van der Worp dan van Gijn (2007) dimana mereka menyatakan bahwa insidensi stroke meningkat secara eksponensial sesuai dengan pertambahan umur. ${ }^{13}$

Pada Tabel 4.5, di dapatkan data bahwa kasus stroke terbanyak terdapat pada bulan Agustus yaitu dengan 10 kasus (13,5\%), lalu pada bulan April dan Mei dengan 9 kasus (12,2\%), selanjutnya pada bulan September dan Desember dengan 8 kasus (10,8\%), pada bulan Januari dengan 7 kasus $(9,5 \%)$, pada bulan Februari dan Oktober dengan 6 kasus (8,1\%), lalu pada bulan Juni dan November dengan 4 kasus (5,4\%), pada bulan Juli dengan 2 kasus (2,7\%), dan yang tersedikit terjadi pada bulan Maret dengan 1 kasus (1,3\%). Hal ini menunjukan bahwa sebaran jumlah penderita stroke infark sepanjang periode Januari 2011-Desember 2011 tidak menunjukan adanya suatu pola yang khas karena jumlah periode tersebar pada setiap bulan. 
Tjikoe, Loho, Ali; Gambaran Hasil CT-Scan Kepala pada Penderita...

\section{SIMPULAN}

Berdasarkan hasil penelitian yang dilakukan di Bagian Radiologi FK. Unsrat / SMF Radiologi BLU RSUP. Prof. Dr. R.D Kandou Manado periode Januari 2011 Desember 2011, didapatkan data mengenai profil penderita stroke infark periode Januari 2011-Desember 2011 adalah sebagai berikut:

1. Pasien yang di diagnosis Radiologi dengan stroke infark berjumlah 74 pasien atau $45,4 \%$.

2. Pasien Stroke Infark terbanyak adalah pasien laki-laki dengan jumlah 44 pasien atau $59,5 \%$

3. Kelompok umur yang terbanyak menderita stroke adalah pada kelompok umur 60-79 tahun dengan 33 pasien atau $44,6 \%$

4. Lokasi lesi yang paling banyak adalah pada lobus parietalis dextra dengan 8 pasien atau 10,8\%.Kasus per bulan terbanyak terdapat pada bulan Agustus dengan 10 kasus atau 13,5\%.

\section{DAFTAR PUSTAKA}

1. Sidharta P. Neurologi klinis dalam praktek umum. Cetakan ketujuh. Jakarta: Dian Rakyat;2009:261

2. Messing R. Nervous System Disorder. In : Hammer GD, McPhee SJ, editors. Pathophysiologi of disease : an introduction to clinical medicine. $6^{\text {th }}$ ed. China: The McGraw-Hill Companies; 2010:169-75

3. Boss B. Disorders of the Central and Peripheral Nervous Systems and the Neuromuscular Junction. In : Brashers VL, Huether SE, McCance KL, Rote NS, editors. Pathophysiology : The biologic basis for disease in adults and children. $6^{\text {th }}$ ed. USA: Mosby Elseiver; 2010: 536-600.

4. Barnes MP, Bogousslavsky J, and Dobki BH. Stroke : Background, epidemiology, etiology, and avoiding reccurence. Published by Cambridge University Press 2005:1

5. Badan Penelitian dan Pengembangan Kesehatan Departemen Kesehatan, Republik Indonesia. Riset Kesehatan Dasar 2007

6. Junaidi I. Stroke Akut. In : Tandung D. Stroke, waspadai ancamannya. $1^{\text {st }}$ ed. Yogyakarta: Penerbit ANDI;2012:13-5

7. Wulandari P. Hubungan Antara Lamanya Waktu Pengambilan CT Scan dan Terjadinya Gambaran Infark Pada Stroke Non Hemoragik di RSUD Dr. Moewardi Surakarta. [skripsi] Surakarta:FKUniversitas Sebelas Maret;2009

8. Mardjono M, Sidharta P. Neurologi Klinis Dasar. $15^{\text {th }}$ ed. Jakarta: Dian Rakyat;2012:291-2

9. Sembiring K. Hubungan Kelainan Jantung Dengan Stroke Iskemik Pada Pasien Rawat Inap Di BagianNeurologiFk-Usu/ Rsup Haji Adam Malik Medan. [skripsi] Medan: FKUniversitas Sumatera Utara;2010

10. Arboix A, Padilla I, Massons J, GarciaEroles L, Comes E, and Targa C, 2001. Clinical Study of 222 Patients with Pure Motor Stroke. J Neurol Neurosurg Psychiatry, 71: 239-242

11. Feigin V.L, Wiebers D.O, Nikitin Y.P, O’Fallon M, and Whisnant J.P, 1998. Risk Factors for Ischemic Stroke in a Russian Community: a Population-based CaseControl. Stroke, 29: 34-9

12. Pendlebury S, Giles $M$, Rothwell P. Transient Ischemic Attack and Stroke: Diagnosis, Investigation and Management. Cambridge University Press:2009

13. Van der Worp H, Van Gijn J. 2007. Acute Ischemic Stroke. New England Journal Medicine,357:572-9. 